\title{
Raiva em bovino associada a intoxicação espontânea por Sida carpinifolia
}

\author{
Rabies in bovine poisoned by Sida carpinifolia
}

\author{
Renata Assis Casagrande ${ }^{\mathrm{I}}$ Flademir Wouters ${ }^{\mathrm{I}}$ Fabiana Marques Boabaid ${ }^{\mathrm{I}}$ Nadia Aline Bobbi Antoniassi ${ }^{\mathrm{I}}$ \\ Saulo Petinatti Pavarini ${ }^{I}$ Luiz Gustavo Schneider de Oliveira' ${ }^{\mathrm{I}}$ Paulo Mota Bandarra ${ }^{\mathrm{I}}$ \\ Priscila Zlotowski $^{\mathrm{I}}$ David Driemeier ${ }^{\mathrm{I}^{*}}$
}

\begin{abstract}
- NOTA -
RESUMO

Dois bovinos, fêmeas, mestiças, 6 anos (caso 1) $e$ 18 meses (caso 2) de idade mantidos em pastagem com intensa invasão por S. carpinifolia apresentaram dificuldade locomotora com inicio nos membros pélvicos progredindo para decúbito esternal ou lateral, nistagmo, tremores e fasciculação de cabeça em um período de quatro a cinco dias. No exame histológico evidenciou-se meningoencefalite $e$ ganglioneurite não supurativa com corpúsculos de Negri em neurônios do cerebelo, tronco encefálico, hipocampo, gânglio trigeminal e medula espinhal. Havia vacuolização citoplasmática nas células de Purkinje e nos neurônios do gânglio trigeminal. A imunofluorescência direta (IFD) para raiva foi positiva nos dois bovinos e na imuno-histoquímica (IHQ) houve marcação do antígeno rábico nos neurônios do

tremors, and fasciculation of the head for four to five days. Histologically was observed meningoencephalitis and ganglioneuritis nonsuppurative with Negri corpuscles in the neurons of the cerebellum, brain steam, hippocampus, trigeminal ganglion and spinal cord. Another histological finding was a cytoplasmic vacuolation of the Purkinje cells and in the trigeminal ganglion neurons. Direct immunofluorescence (DIF) for rabies viral antigen was positive in both animals and anti-rabies immunohistochemistry (IHC) was positive in the neurons of the cerebellar and cerebral cortex, hippocampus, and trigeminal ganglion. Con- $A, W G A$, and sWGA lectin histochemistry were positive in the vacuolated neurons. Based on the morphological and epidemiological features, rabies DIF and IHC, and lectin histochemistry the present report consists of two cases of subclinical poisoning with $\mathbf{S}$. carpinifolia in cattle infected with rabies virus.
\end{abstract} córtex cerebelar e cerebral, hipocampo e gânglio trigeminal. A histoquímica com lectinas evidenciou que o citoplasma vacuolizado dos neurônios apresentaram marcação para ConA, WGA e sWGA. De acordo com os achados morfológicos, os epidemiológicos, a IHQ e a IFD para raiva e o padrão histoquímico com lectinas conclui-se que o presente relato representa dois casos subclínicos de intoxicação por $\mathbf{S}$. carpinifolia em bovinos com infecção pelo vírus da raiva.

Palavras-chave: doença de bovinos, sistema nervoso central, doença de depósito lisossomal, Lyssavirus.

\section{ABSTRACT}

Two female bovine, crossbreed, 6-year-old (case 1) and 18-month-old (case 2) grazing in pasture infested by Sida carpinifolia showed gait difficulties, initially at the pelvic limbs, progressing to sternal or lateral decumbency, nystagmus,
Key words: disease in cattle, central nervous system, lisosomal storage disease, Lyssavirus.

A raiva é a principal causa de encefalite em bovinos no Sul do Brasil (SANCHES et al., 2000). Essa enfermidade ocorre frequentemente em herbívoros, e morcegos hematófagos são os principais transmissores para essas espécies, que desenvolvem uma doença geralmente paralítica associada a lesões na medula espinhal, tronco encefálico e cerebelo.

Sida carpinifolia (guanxuma, chá-da-índia), uma planta invasora de pastagens e lavouras, contem

ISetor de Patologia Veterinária (SPV), Faculdade de Veterinária (FAVET), Universidade Federal do Rio Grande do Sul (UFRGS), Av. Bento Gonçalves, 9090, 91540-000, Porto Alegre, RS, Brasil. E-mail: davetpat@ufrgs.br. *Autor para correspondência. 
o alcaloide swainsonina, que inibe a enzima alfamanosidase lisossômica e causa uma doença de depósito lisossomal (DDL) caracterizada pelo acúmulo de oligossacarídeos nos lisossomos (COLODEL et al., 2002a). Essa enfermidade ocorre de forma espontânea em caprinos (DRIEMEIER et al., 2000; COLODEL et al., 2002b) e bovinos (FURLAN et al., 2009; PEDROSO et al., 2010).

Nesse trabalho descreve-se o quadro clínico e anatomopatológico de dois casos de raiva em bovinos com intoxicação espontânea subclínica por Sida carpinifolia. Os dados epidemiológicos e sinais clínicos foram obtidos junto aos proprietários e aos médicos veterinários responsáveis. Realizou-se visita às propriedades para levantamento de dados e realização da necropsia dos bovinos. Fragmentos de todos os órgãos foram coletados, fixados em formalina a $10 \%$ e processados rotineiramente para histologia. Fragmentos encéfalo, gânglio trigeminal e medula espinhal foram submetidos à imunofluorescência direta (IFD) para raiva, à técnica de imuno-histoquímica (IHQ) para raiva (PEDROSO et al., 2008) e de histoquímica com lectinas Concanavalia ensiformis (Con-A), Triticum vulgaris (WGA) e Succinil WGA (sWGA) (COLODEL et al., 2002b).

A primeira propriedade visitada localizavase no município de Maquiné (RS), em uma região com furnas e possuía apenas três bovinos destinados à produção de leite que eram mantidos em pastagem nativa com intensa invasão por $\boldsymbol{S}$. carpinifolia. Dois bovinos, fêmeas, mestiças, 2 e 6 anos de idade, apresentaram paralisia progressiva, inicialmente nos membros posteriores que evoluiu para decúbito esternal em dois dias e morte cinco dias após. Realizouse necropsia no bovino fêmea de 6 anos (caso 1), no qual foi observado sinais de sugadura de morcego na região torácica próximo as escápulas.

A segunda propriedade visitada localizavase no município de Triunfo (RS) e possuía um rebanho de aproximadamente 30 bovinos de corte que eram mantidos em área de reflorestamento por Acácia negra (Acacia sp.) com intensa invasão por $\boldsymbol{S}$. carpinifolia . O rebanho tinha sido vacinado para raiva seis meses antes e não havia histórico de doença prévia. Um bovino, fêmea, 18 meses, mestiça (caso 2) apresentou dificuldade locomotora com inicio nos membros pélvicos progredindo para decúbito lateral em um período de quatro dias. O animal não possuía sensibilidade nos membros pélvicos e apresentava nistagmo, tremores e fasciculação de cabeça. Realizouse a eutanásia in extremis e na necropsia observou-se a bexiga repleta e o intestino com conteúdo ressecado, muco e sangue na porção final.
Na avaliação histológica do encéfalo havia infiltrado perivascular linfoplasmocitário e poucos macrófagos multifocal discreto no cerebelo (casos 1 e 2) e tronco encefálico (caso 2), moderado na medula espinhal (caso 2) e acentuado no cérebro (caso 1). No cerebelo evidenciou-se infiltrado linfoplasmocitário discreto nas leptomeninges (caso 2). No tronco encefálico (caso 2), no córtex cerebral e no hipocampo (caso 1) havia gliose multifocal discreta com satelitose e necrose neuronal. No gânglio trigeminal observouse infiltrado linfoplasmocitário multifocal moderado (caso 2) e difuso acentuado (caso 1) com necrose neuronal e esferóides axonais (casos 1 e 2). Corpúsculos de Negri foram observados em grande quantidade nas células de Purkinje (Figura 1A) e em alguns neurônios de Golgi no cerebelo (casos 1 e 2), e nos neurônios do tronco encefálico (caso 2), hipocampo (casos 1 e 2), gânglio trigeminal (caso 1) e medula espinhal (caso 2). Além disso, evidenciou-se no cerebelo vacuolização citoplasmática difusa acentuada nas células de Purkinje (casos 1 e 2) (Figura 1A) e nos neurônios do gânglio trigeminal multifocal moderada (caso 1).

Os resultados de IFD para raiva dos dois bovinos foram positivos. Na IHQ houve marcação do antígeno rábico nos neurônios do córtex cerebral, hipocampo e gânglio trigeminal (caso 1), nos neurônios de Purkinje e seus processos na camada molecular e na camada granular e nos neurônios de Golgi (caso 2) (Figura 1B), caracterizada por agregados granulares ou em forma arredonda em grande quantidade no pericário e prolongamentos.

Quanto a histoquímica das lectinas, evidenciou-se o citoplasma vacuolizado dos neurônios do cérebro e gânglio trigeminal com marcação difusa moderada (caso 1) e das células de Purkinje e neurônio de Golgi difusa acentuada (caso 2) para Con-A (Figura 1C), WGA e sWGA.

A raiva causa uma doença fatal em bovinos e o diagnóstico é estabelecido pela visualização dos corpúsculos de Negri, IFD ou IHQ. Infecções pelo vírus da raiva associada com outros agentes não são comumente reportadas. Há um relato de raiva em um bovino de um ano de idade em que foi isolado Herpesvírus bovino tipo 5 (BHV-5) do encéfalo, no entanto não foi possível determinar se o BHV-5 teve algum papel no desfecho do caso já que esse vírus poderia estar latente no tecido encefálico (SPILKI et al., 2003).

No presente relato os bovinos apresentaram quadro clínico neurológico e histopatológico que são característicos da infecção fatal pelo vírus da raiva, no entanto observou-se também vacuolização 


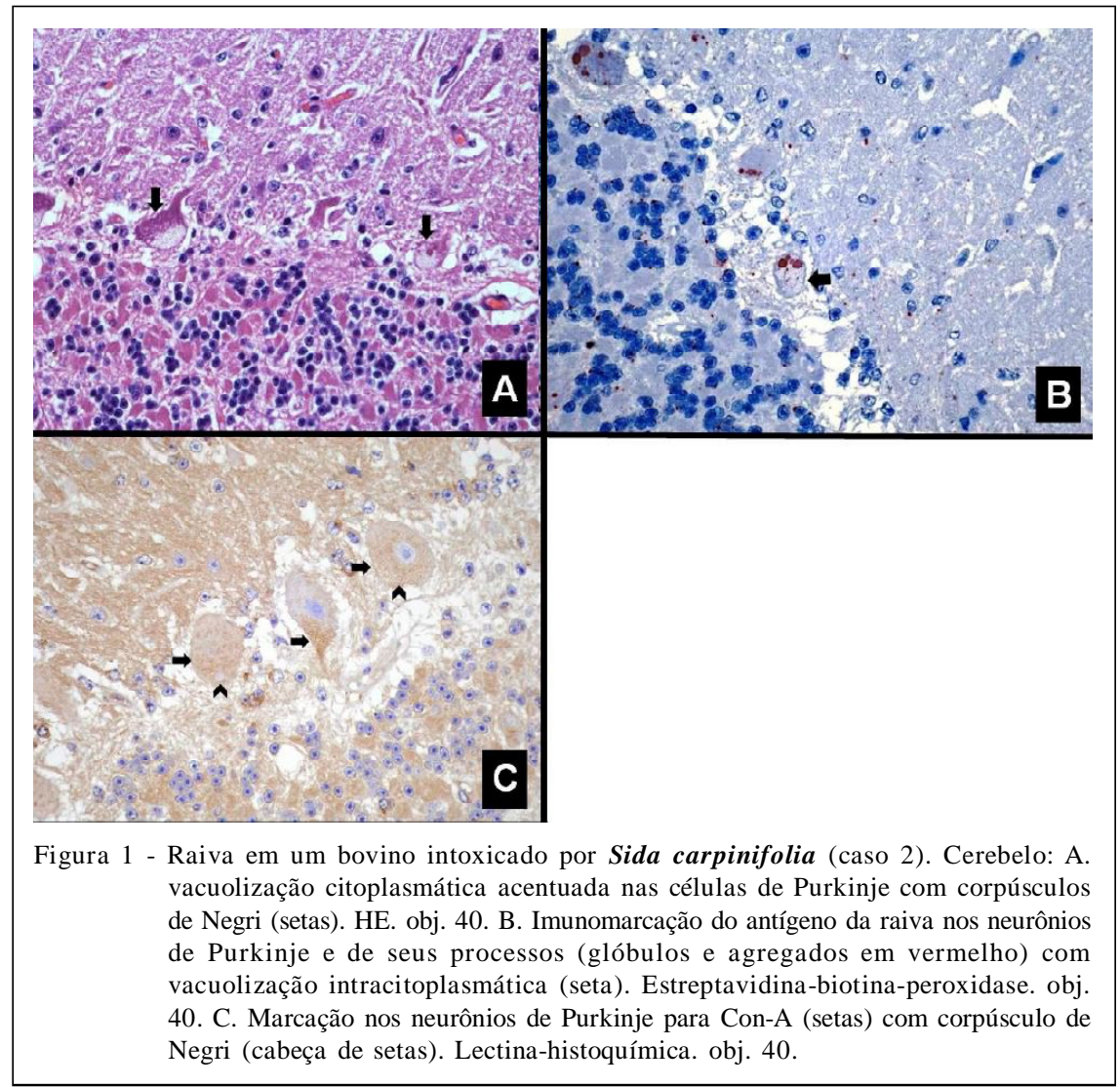

citoplasmática dos neurônios. Essas foram marcadas pelas lectinas que caracterizam uma DDL com acúmulo de oligossacarídeos. Esses bovinos encontravam-se em um ambiente com grande quantidade de $\boldsymbol{S}$. carpinifolia, todavia não apresentavam alterações clínicas típicas de DDL caracterizadas por distúrbios crônicos de propriocepção, tremores e incoordenação motora (FURLAN et al., 2009). Portanto, o quadro clínico nesses bovinos provavelmente se devia à infecção pelo vírus rábico.

A vacuolização encontrada nos neurônios marcada pelas lectinas pode ter sido um achado incidental. COLODEL et al. (2002b) reproduziram experimentalmente a intoxicação por Sida carpinifolia em três caprinos e, um desses não apresentou alterações clínicas durante os 90 dias do experimento, no entanto no exame histológico havia lesões de DDL. FURLAN et al. (2008) reproduziram experimentalmente a intoxicação por esta planta em cinco bovinos e os sinais clínicos foram observados em dois bovinos que ingeriram diariamente $30 \mathrm{~g} \mathrm{~kg}^{-1} \mathrm{e} 40 \mathrm{~g} \mathrm{~kg}^{-1}$ apenas a partir do $99^{\circ}$ e $77^{\circ}$ dias de experimentação, respectivamente. Sendo assim, se os bovinos do presente relato continuassem ingerindo a planta por um período maior os sinais clínicos de DDL poderiam aparecer e levá-los a morte.

De acordo com os achados morfológicos, a IHQ e IFD para raiva e a histoquímica das lectinas conclui-se que o presente relato trata-se de dois casos subclínicos de intoxicação por $\boldsymbol{S}$. carpinifolia em bovinos com raiva. Nessa espécie, não há relatos anteriores de lesão encefálica mista causada pelo vírus da raiva associada a um outro agente.

\section{AGRADECIMENTOS}

A médica veterinária Laura R. B. Barreto da Secretaria da Agricultura do município de Triunfo pela disponibilização de um dos casos para este estudo. Ao Instituto de Pesquisas Veterinárias Desidério Finamor (IPVDF) pelos resultados de IFD de raiva dos materiais encaminhados.

\section{REFERÊNCIAS}

COLODEL, E.M. et al. Identification of Swainsonine as a glycoside inhibitor responsible for Sida carpinifolia poisoning. Veterinary \& Human Toxicology, v.44, p.177-178, 2002a.

COLODEL, E.M. et al. Aspectos clínicos e patológicos da intoxicação por Sida carpinifolia (Malvaceae) em caprinos no Rio Grande do Sul. Pesquisa Veterinária Brasileira, v.22, n.2, p.51-57, 2002 b. 
Disponível em: <http://www.scielo.br/scielo.php?pid=S0100736X2002000200004\&script=sci_arttext $>$. Acesso em: 10 jul. 2011. doi:10.1590/S0100-736X2002000200004.

DRIEMEIER, D. et al. Lysosomal storage disease caused by Sida carpinifolia poisoning in goats. Veterinary Pathology, v.37, p.153-159, 2000. Disponível em: <http://vet.sagepub.com/ content/37/2/153.full>. Acesso em: 10 jul. 2011. doi:10.1354/ vp.37-2-153.

FURLAN, F.H. et al. Intoxicação experimental por Sida carpinifolia (Malvaceae) em bovinos. Pesquisa Veterinária Brasileira, v.28, p.57-62, 2008. Disponível em: <http:// www.scielo.br/scielo.php? script $=$ sci_arttext $\&$ pid $=S 0100-$ 736X2008000100009>. Acesso em: 10 jul. 2011. doi:10.1590/ S0100-736X2008000100009.

FURLAN, F.H. et al. Spontaneous lysosomal storage disease caused by Sida carpinifolia (Malvaceae) poisoning in cattle. Veterinary Pathology, v.46, p.343-347, 2009. Disponível em: <http://vet.sagepub.com/content/46/2/343.full>. Acesso em: 10 jul. 2011. doi:10.1354/vp.46-2-343.

PEDROSO, P.M.O. et al. Padronização da técnica de imunohistoquímica para raiva em amostras de sistema nervoso central de bovinos fixados em formol e emblocados em parafina. Pesquisa Veterinária Brasileira, v.28, p.627-632, 2008 Disponível em: <http://www.scielo.br/scielo.php?pid=S0100736X2008001200012\&script $=$ sci_arttext $>$. Acesso em: 09 set. 2011. doi:10.1590/S0100-736X2008001200012.

PEDROSO, P.M.O. et al. Doença do armazenamento lisossomal induzida pelo consumo de Sida carpinifolia em bovinos do Rio Grande do Sul. Pesquisa Veterinária Brasileira, v.30, n.10, p.833-838, 2010. Disponível em: <http://www.scielo.br/ scielo.php?script=sci_arttext\&pid=S0100-736X2010001000005 >. Acesso em: 10 jul. 2011. doi:10.1590/S0100-736X2010001000005.

SANCHES, A.W.D. et al. Doenças do sistema nervoso central em bovinos no Sul do Brasil. Pesquisa Veterinária Brasileira, v.20, n.3, p.113-118, 2000. Disponível em: <http:/ /www.scielo.br/scielo.php?script $=$ sci_arttext\&pid $=S 0100$ 736X2000000300005>. Acesso em: 10 jul. 2011. doi:10.1590/ S0100-736X2000000300005.

SPILKI, F.R. et al. Bovine herpesvirus type 5 (BHV-5) in a calf with rabies. Pesquisa Veterinária Brasileira, v.23, n.1, p.1-4, 2003. Disponível em: <http://www.scielo.br/scielo.php?pid=S0100736X2003000100001\&script=sci_abstract $>$. Acesso em: 10 jul. 2011. doi:10.1590/S0100-736X2003000100001. 